\title{
IEDITORIAL
}

\section{Intravascular access routes while wearing personal protective equipment: are we close to the bone or not?}

\author{
Matteo Paganini', Claudio Dalla Vecchia², Maycol Franco ${ }^{1}$ \\ 1 Division of Emergency Medicine, Department of Medicine (DIMED), University of Padua, Padua, Italy \\ 2 Emergency Department, Mater Misericordiae University Hospital, Dublin, Ireland
}

\section{RELATED ARTICLE}

by Drozd et al, see p. 277
Correspondence to: Matteo Paganini, MD, Division of Emergency Medicine, Department of Medicine (DIMED), University of Padua, Via Giustiniani, 2, 35128 Padova, Italy, phone: +390498218693, email: matteo.paganini@unipd.it Received: February 19, 2021. Accepted: February 20, 2021. Published online: March 25, 2021. Kardiol Pol. 2021; 79 (3): 246-247 doi:10.33963/KP.15890 Copyright by the Author(s), 2021
After its discovery in the early 20th century, the use of intraosseous access was described in small groups of noncritically ill patients, particularly children. After World War II, the introduction of disposable intravenous catheters superseded intraosseous access until the late 1990s, when its use as a fast and reliable infusion route in the prehospital arena prompted further investigations. ${ }^{1}$

The debate on the use of peripheral venous access (PVA) versus intraosseous access has become of great interest, since the latter is increasingly used in emergency medicine and critical care. In these fields, time is of the essence, and the current indications for intraosseous access include:

- cardiac arrest or severe shock in infants or children, when PVA is not readily available ${ }^{2}$

- failure to obtain PVA after multiple attempts during life-threatening conditions in which intravascular access is essential (eg, multiple trauma, severe shock, extensive burns, and in tactical medicine $)^{3}$

- cardiac arrest in adults (updated in 2020: intraosseous access recommended after failure to obtain PVA) ${ }^{4}$

More broadly, when PVA is not available, and multiple attempts have failed, intraosseous access overcomes the central venous access by its rapidity of placement, ${ }^{5}$ while ensuring the same pharmacokinetics ${ }^{6}$ and enabling prompt patient stabilization.

While working with personal protective equipment (PPE), common procedures such as obtaining vascular access may become more laborious. The use of high-level PPE has been usually confined to the field of Chemical-Biological-Radiological-Nuclear-explosives (CBRNe) threats. However, the Ebola outbreak and the current COVID-19 pandemic forced healthcare personnel to work using PPE, bringing to the fore the manual impairment while performing procedures and the need for dedicated training. ${ }^{7,8}$ In this issue of Kardiologia Polska (Kardiol Pol, Polish Heart Journal), Drozd et $\mathrm{al}^{9}$ conducted the first meta-analysis to evaluate intravascular access time-to-placement and success rates in PPE-restricted scenarios. The authors included clinical, cadaver, and simulation trials. Five studies directly compared intraosseous access and PVA procedure duration, and 3 studies compared the success rates of insertion, with and without PPE. The results showed longer procedure duration measured in seconds (mean difference, $-41.43 ; 95 \% \mathrm{CI}$, -62.36 to $-24.47 ; P<0.001)$ yet similar success rates $(100 \%$ vs $90.3 \%$; risk ratio, $1.08 ; 95 \%$ CI, $0.97-1.2 ; P=0.18)$ while wearing PPE. The authors also looked at subanalysis among medical staff, paramedics, and other providers.

Overall, the authors concluded that the use of PPE significantly extends the duration of both intravascular access procedures and that intraosseous access can be obtained faster and with a higher success rate compared with PVA. These results are consistent with those obtained by Mormando et $\mathrm{al}^{10}$ in a randomized manikin trial, not included in the meta-analysis by Drozd et al, ${ }^{9}$ where intraosseous access procedure duration appeared to supersede PVA with and without PPE. 
Some important considerations other than procedure time and success rates should be taken into account when deciding which vascular access modality to consider while wearing PPE. Intraosseous access cannot be left in place for more than 24 hours owing to the risk of osteomyelitis, ${ }^{11}$ thus requiring another vascular access, either peripheral or central venous access, to be obtained. ${ }^{12}$ This is particularly relevant in patients affected by COVID-19, who usually have a prolonged hospital stay. Therefore, it seems reasonable that the intraosseous access route should not be routinely used in COVID-19 and, more broadly, while wearing PPE. In those cases, PVA should be attempted if patient conditions allow a slower-than-usual placement, and intraosseous access should be reserved for critical patients or failed PVA attempts.

Furthermore, in patients who have experienced out-of-hospital cardiac arrest, a recent review of 6 observational studies and the subgroup analysis of 2 randomized controlled trials concluded that PVA is associated with higher survival to discharge and better neurological outcomes than intraosseous access. ${ }^{13}$ This evidence prompted the update of the 2020 Adult Advanced Life Support guidelines: PVA is now recommended as the first attempt during cardiac arrest, ${ }^{4}$ and intraosseous access should not be used as the first route.

As Drozd et $\mathrm{al}^{9}$ rightly point out, the absence of human studies in the meta-analysis is a major limitation that could affect the generalizability of the results. Several researchers have previously highlighted this controversy, increasingly found in the literature from high-clinical risk fields like emergency medicine or critical care. Indeed, manikins for medical simulation and research help avoid unnecessary hazards to real patients while adding relevant information to the body of knowledge. Nevertheless, bench-to-bedside research and community clinical research have become essential parts of the healthcare system, and future efforts should be made to start human trials addressing the questions posed by Drozd et al. ${ }^{9}$ Also, the success rate in manikin trials is difficult to define, and the anatomical site of insertion and the device used for obtaining intraosseous access affected the success rate in some studies, ${ }^{14}$ adding other sources of variability that Drozd et $\mathrm{al}^{9}$ could not address owing to the small number of papers found.

Finally, intraosseous access or PVA time-to-placement per se might not be as relevant as other patient-oriented outcomes, especially when the mean difference between the 2 routes is only 41 seconds. ${ }^{9}$ It is hard to imagine that such a small difference could contribute to the overall patient morbidity and mortality. Nevertheless, intraosseous access is a fast and reliable intravascular access, still of the essence in CBRNe major incidents-in which the number of victims exceeds the number of healthcare providers - tactical and military medicine, and in critically ill patients.

Overall, the meta-analysis by Drozd et $\mathrm{al}^{9}$ demonstrates that intraosseous access is slightly faster and has similar success rates compared with PVA while wearing PPE. Still, providers should also bear in mind the limitations of intraosseous access, especially when dealing with patients affected by COVID-19.

\section{ARTICLE INFORMATION}

DISCLAIMER The opinions expressed by the author(s) are not necessarily those of the journal editors, Polish Cardiac Society, or publisher.

NOTE An online identifier was assigned to MP (ORCiD ID, 0000-0002-7556-6928). CONFLICT OF INTEREST None declared.

OPEN ACCESS This is an Open Access article distributed under the terms of the Creative Commons Attribution-NonCommercial-NoDerivatives 4.0 International License (CC BY-NC-ND 4.0), allowing third parties to download articles and share them with others, provided the original work is properly cited, not changed in any way, distributed under the same license, and used for noncommercial purposes only. For commercial use, please contact the journal office at kardiologiapolska@ptkardio.pl.

HOW TO CITE Paganini M, Dalla Vecchia C, Franco M. Intravascular access routes while wearing personal protective equipment: are we close to the bone or not? Kardiol Pol. 2021; 79: 246-247. doi:10.33963/KP.15890

\section{REFERENCES}

1 Burgert JM. A primer on intraosseous access: history, clinical considerations, and current devices. Am J Disaster Med. 2016; 11: 167-173.

2 Maconochie IK, Aickin R, Hazinski MF, et al. Pediatric life support: 2020 international consensus on cardiopulmonary resuscitation and emergency cardiovascular care science with treatment recommendations. Circulation. 2020; 142 (suppl 1): S140-S184.

3 Luck RP, Haines C, Mull CC. Intraosseous access. J Emerg Med. 2010; 39: 468-475.

4 Berg KM, Soar J, Andersen LW, et al; Adult Advanced Life Support Collaborators. Adult advanced life support: 2020 international consensus on cardiopulmonary resuscitation and emergency cardiovascular care science with treatment recommendations. Circulation. 2020; 142 (suppl 1): S92-S139.

5 Lee PM, Lee $C$, Rattner $P$, et al. Intraosseous versus central venous catheter utilization and performance during inpatient medical emergencies. Crit Care Med. 2015; 43: 1233-1238.

6 Hoskins SL, do Nascimento P Jr, Lima RM, et al. Pharmacokinetics of intraosseous and central venous drug delivery during cardiopulmonary resuscitation. Resuscitation. 2012; 83: 107-112.

7 Ragazzoni L, Ingrassia PL, Echeverri L, et al. Virtual reality simulation training for Ebola deployment. Disaster Med Public Health Prep. 2015; 9: 543-546.

8 Carenzo L, Costantini E, Greco M, et al. Hospital surge capacity in a tertiary emergency referral centre during the COVID-19 outbreak in Italy. Anaesthesia. 2020; 75: 928-934.

9 Drozd A, Smereka J, Filipiak KJ, et al. Intraosseous versus intravenous access while wearing personal protective equipment: a meta-analysis in the era of COVID-19. Kardiol Pol. 2021; 79: 277-286.

10 Mormando G, Paganini M, Alexopoulos C, et al. Life-saving procedures performed while wearing CBRNe personal protective equipment: a mannequin randomized trial. Simul Healthc. 2021 Jan 8. [Epub ahead of print].

11 Rosetti VA, Thompson BM, Miller J, et al. Intraosseous infusion: an alternative route of pediatric intravascular access. Ann Emerg Med. 1985; 14: 885-888.

12 Anson JA. Vascular access in resuscitation: is there a role for the intraosseous route? Anesthesiology. 2014; 120: 1015-1031.

13 Granfeldt A, Avis SR, Lind PC, et al. Intravenous vs. intraosseous administration of drugs during cardiac arrest: a systematic review. Resuscitation. 2020; 149: 150-157.

14 Reades R, Studnek JR, Vandeventer S, Garrett J. Intraosseous versus intravenous vascular access during out-of-hospital cardiac arrest: a randomized controlled trial. Ann Emerg Med. 2011; 58: 509-516. 